\title{
GORRESPONDENGE
}

\section{Hysterectomy-A Comparison of Approaches}

by PD Dr. med. Andreas Müller, Dr. med. Falk C. Thiel,

Dr. med. Stefan P. Renner, Dr. med. Mathias Winkler, Dr. rer. nat. Lothar Häberle, Prof. Dr. med. Matthias W. Beckmann in volume 20/2010

\section{Patient Welfare}

The review article of interest to gynecologists cannot pass without comment, as the Department of Obstetrics and Gynecology, Erlangen University Hospital, occasionally makes seemingly radical statements on the relationship between quantity and quality. Luckily, these do not remain unchallenged (1).

The 140 "simple" hysterectomies per year are divided among the large number of doctors at a single university hospital. For reasons stated above, we may therefore ask how the above-mentioned relationship arises. It would have been interesting to know how many operations were performed by a single surgeon.

Financial and medical issues relating to operating times, which seem very long (why does a vaginal hysterectomy take so long?) should also be carefully scrutinized.

With an average hospital stay of ten days following abdominal hysterectomy, it is clear where there is still potential for savings, not to mention how good the relationship with Germany's Medical Service for Health Insurers must be to avoid drowning in a flood of inquiries: "tu felix universitas?"

In summary, Prof. Egger may be quoted (2): "...mainly a medical discussion as to whether a total hysterectomy...is necessary,” and “...total vaginal hysterectomy...the simplest, fastest operation, and...the operation with fewest side effects."

There is little to add to this. These and his other comments regarding his own experience must not prevent one from asking whether the high number of LASHes (laparoscopically-assisted supracervical hysterectomies), LAVHes (laparoscopically-assisted vaginal hysterectomies), and TLHs (total laparoscopic hysterectomies) are genuinely in the oft-mentioned interests of patients.

D0l: 10.3238/arztebl.2010.0796a

\section{REFERENCES}

1. Enderer-Steinfort G: Gynäkologische Krebszentren - Wie viel brauchen wir wirklich? Frauenarzt 2010; 51: 407-9.

2. Egger H: Suprazervikale oder totale Hysterektomie? Gynäkol Prax 2010; 34: 205-7.

3. Müller A, Thiel FC, Renner SP, Winkler M, Häberle L, Beckmann MW: Hysterectomy —A comparison of approaches. Dtsch Arztebl Int 2010; 107(20): 353-9

Dr. med. Ulrich Steigerwald

Enzkreis-Kliniken Mühlacker

Hermann-Hesse Str. 34

75417 Mühlacker, Germany

Zahira.Azzam@kliniken-ek.de

\section{The Marketing Effect}

In industrialized countries, the rates of hysterectomies as treatment for benign diseases of the uterus have fallen in the last twenty years due to the use of methods which preserve the uterus (IUDs with progestogen, endometrial ablation, myomectomy, etc.). In contrast, the study by Müller et al. reported an explosion in hysterectomy rates at one institution after laparoscopic methods (laparoscopic hysterectomy [LH] and laparoscopic supracervical hysterectomy [LSH]) were introduced, in 2004 to 2008. This huge increase can only be explained by a marketing effect ("new operation-new patients”) and more frequent indication of the procedure. The advantages of LH and LSH stated are low blood loss and short operating time, but these are not clinically significant.

Day-to-day clinical practice, confirmed by numerous studies, shows that vaginal hysterectomy by an experienced surgeon is the method requiring the shortest operating time, lowest consumption of resources, and highest patient satisfaction. However, laparoscopic methods have a powerful ally: the industry, which has an interest in promoting laparoscopic surgery, despite its high consumption of resources. Intensive marketing supported by the industry keeps the profile of laparoscopic hysterectomy methods constantly high by means of surgery courses on the subject for many and varied indications. Unlike LH and LSH, vaginal hysterectomy requires no specific instruments or newly available techniques, and thus offers few chances for marketing. This is very much to the detriment of women who need to have their wombs removed due to benign diseases, because vaginal hysterectomy leaves no scarring and removes the whole cervix, which might otherwise develop abnormalities that require repeat surgery. Vaginal hysterectomy should therefore remain the focus of professional training for gynecology surgeons, as it provides the most benefits for patients.

DOI: 10.3238/arztebl.2010.0796b

\section{REFERENCES}

1. Müller A, Thiel FC, Renner SP, Winkler M, Häberle L, Beckmann MW: Hysterectomy-A comparison of approaches. Dtsch Arztebl Int 2010; 107(20): 353-9.

Prof. Dr. med. Johannes Diet

Universitäts-Frauenklinik

Josef-Schneider-Str. 4

97080 Würzburg, Germany

Markert_F@klinik.uni-wuerzburg.de

or: frauenklinik@mail.uni-wuerzburg.de 


\section{Six Authors}

In assessing new approaches to hysterectomy, one of the authors' conclusions is that vaginal hysterectomy and laparoscopic methods (laparoscopically-assisted supracervical hysterectomy [LASH] and total laparoscopic hysterectomy [TLH]) are equally valid alternatives. As vaginal hysterectomy showed significantly shorter operating times and the lowest total rate of intraoperative and postoperative complications, this seems doubtful. Also, a supporter of the school of vaginal surgery would wonder why the potential of vaginal hysterectomies for the presented disease profile has not been fully explored, and why a vaginal approach is not selected more often. Although the size and flexibility of the uterus restrict vaginal access, if only 74 vaginal hysterectomies were performed over seven years (2002 to 2008)-as compared to 413 TLHs-ten or eleven operations per year make this surgery a rare event. Admittedly, including cases which meet exclusion criteria (other operations in addition to hysterectomy) qualifies this suspicion. However, even on this basis there are 958 abdominal operations (excluding LASHes) and “only” 377 vaginal hysterectomies (58 cases per year), and these are divided among several surgeons; only six authors were involved with the published article. If surgery were carried out more frequently, initial conditions (size of uterus, spatial proportions) could be better understood, technique (morcellation) and results (operating time, blood loss, complication rate) could be improved, and more patients could be offered vaginal hysterectomies. If only half of the 413 patients who underwent TLHs (average operating time 108 minutes) had been operated on vaginally (operating time 87 minutes), 72 hours of operating time could have been saved. In addition, the women in question would have been spared the disadvantages of laparoscopic surgery (surgery in the head-down position, several small abdominal incisions, gas insufflation, administration of anesthesia, length of anesthesia).

DOI: 10.3238/arztebl.2010.0797a

\section{REFERENCES}

1. Müller A, Thiel FC, Renner SP, Winkler M, Häberle L, Beckmann MW: Hysterectomy — A comparison of approaches. Dtsch Arztebl Int 2010; 107(20): 353-9.

Prof. em. Dr. med. Jürgen Nieder

Büchnerstr. 29

39114 Magdeburg, Germany

juergen-nieder@web.de

\section{In Reply:}

At this juncture the authors should be thanked for their critical observations and comments. We have shown that the rate of open hysterectomies can be reduced significantly even at a university training hospital (1). Prof. Dietl criticizes the overall rise in the rate of hysterectomies. The increase in the number of hysterectomies at our hospital is the result of an increase in the total number of cases, not a change in the cases for which it is indicated. In essence, we have demonstrated a shift from abdominal to laparoscopic surgery (1). We have not received any payment from the industry.

Different operating methods are often discussed emotionally by supporters of various schools of surgery. As supporters of the school of vaginal surgery, Dr. Steigerwald, Prof. Dietl and Prof. Nieder demand more vaginal hysterectomies. This is a completely justified demand, but as yet we consider the analysis provided to be not reproducible or evidence-based.

According to the Cochrane meta-analyses conducted in 2006 and 2009, laparoscopic methods have the shortest postoperative recovery phase (return to normal activities) ([12] in the article) (2). The results of two prospective randomized studies show less postoperative pain following laparoscopic hysterectomies than following vaginal hysterectomies $(3,4)$. However, the available data on major long-term parameters such as prolapse and incontinence are as yet insufficient ([12] in the article) (2). The largest cohort study conducted so far regarding incontinence and prolapse following hysterectomy shows that vaginal hysterectomy is associated in particular with the highest rate of operations for stress incontinence and surgery for prolapse following hysterectomy ([5] and [6] in the article). Is this because of the operating method or the risk factors of patients who underwent vaginal hysterectomies? Data with a reasonable level of evidence do not yet provide the answer to this question.

Dr. Steigerwald mentions the supposedly "long” operating time of vaginal hysterectomies. He seems to be referring to the operating time of the surgery-which is commonly 30 minutes-which is often "felt." On the one hand, this does not match the facts according to statistical analysis of large cohorts. On the other, a university hospital is obliged to provide training for new doctors; if it did not, it would not deserve to be called a university hospital. Naturally, some of the operations performed at our establishment are for training purposes. Our published operating times for vaginal hysterectomies are completely in line with the published operating times of other university training hospitals in Germany ([e1] in the article) (5).

Other advantages of laparoscopy include better assessment of the abdomen as a whole (not just the adnexa) and the possibility of performing other operations at the same time in patients with multiple prior operations. In our patient satisfaction questionnaires, none of our patients has complained about the small abdominal incisions, the operating time, or the head-down position during surgery.

Discussion of hysterectomy methods remains tense. However, it must be objective and based on arguments supported by studies with appropriate levels of evidence.

DOl: 10.3238/arztebl.2010.0797b 


\section{REFERENCES}

1. Müller A, Thiel FC, Renner SP, Winkler M, Häberle L, Beckmann MW: Hysterectomy-A comparison of approaches. Dtsch Arztebl Int 2010; 107(20): 353-9.

2. Nieboer TE, Johnson N, Lethaby A, et al.: Surgical approach to hysterectomy for benign gynaecological disease. Cochrane Database Syst Rev 2009; 8(3): CD003677.

3. Ghezzi F, Uccella S, Cromi A, et al.: Postoperative pain after laparoscopic and vaginal hysterectomy for benign gynecologic disease: a randomized trial. Am J Obstet Gynecol. 2010 Jun 2. [Epub ahead of print].

4. Candiani M, Izzo S, Bulfoni A, Riparini J, Ronzoni S, Marconi A: Laparoscopic vs vaginal hysterectomy for benign pathology. Am J Obstet Gynecol 2009; 200(4): 368 e1-7.

5. Altgassen C, Michels W, Schneider A, Diedrich K: Wie sicher ist die laparoskopisch assistierte vaginale Hysterektomie? How safe is laparoscopically assisted vaginal hysterectomy? Geburtsh Frauenheilk 2005; 65: 1051-7.

Dr. med. Falk C. Thiel

Dr. med. Stefan P. Renner

Dr. med. Mathias Winkler

Dr. rer. nat. Lothar Häberle

Prof. Dr. med. Matthias W. Beckmann

PD Dr. med. Andreas Müller

Frauenklinik, Universitätsklinikum Erlangen

Universitätsstr. 21-23

91054 Erlangen, Germany

andreas.mueller@uk-erlangen.de

Conflict of interest statement

The authors declare that no conflict of interest exists according to the

guidelines of the International Committee of Medical Journal Editors. 